\title{
EL PAPEL DE LA CORONA EN EL NOMBRAMIENTO DEL PRIMER MINISTRO BELGA: UN MODELO NO IMPORTABLE*
}

\author{
ÁNGEL J. SÁNCHEZ NAVARRO \\ Catedrático de Derecho Constitucional \\ Universidad Complutense
}

\section{SUMARIO}

I. Introducción. II. La Jefatura de Estado en el nombramiento de los gobiernos parlamentarios III. Los colaboradores de la Corona en la selección de los Primeros Ministros: Países Bajos y Bélgica. IV. Conclusión: un modelo muy discutible, y no importable.

\section{INTRODUCCIÓN}

Los resultados de las elecciones generales celebradas en España el 20 de diciembre de 2015 y el 26 de junio de 2016 dieron lugar, como se ha dicho, a una «legislatura fallida» y a una «investidura convulsa», incapaz de garantizar «la estabilidad y eficacia de la acción gubernamental» ${ }^{1}$. No resulta extraño, en consecuencia, que tanto la sociedad en general como la doctrina constitucional, en particular, prestasen especial atención a las normas, circunstancias y procedimientos que rodean el circuito electoral y parlamentario. Procedimientos que, a partir del pluralismo social y político existente en las sociedades democráticas y abiertas, sirve esencialmente para definir mayorías parlamentarias capaces de cumplir la que, desde los orígenes del parlamentarismo, constituye la primera función de las Cámaras, que - como ya apuntara Bagehot - no es otra que la de sostener a un gobierno ${ }^{2}$.

* In memoriam: a Joaquín Varela Suanzes-Carpegna, a cuyo trabajo tantos debemos tanto.

1 ARAGÓN REYES, M., «Legislatura fallida e investidura convulsa. Análisis y consecuencias», en Revista Española de Derecho Constitucional (en adelante, REDC), $\mathrm{n}^{\circ} 109,2017$, pp. 15 y ss.

2 «La principal [función de la Cámara de los Comunes]», cuya existencia es bien conocida, aunque en el lenguaje constitucional de ella no se trate, es la... electoral: la Cámara de los Comunes es la asamblea que 
En el ámbito doctrinal, tal atención se ha plasmado en la publicación de un elevado número de trabajos científicos que han tratado de analizar críticamente el funcionamiento de esas normas y procedimientos ${ }^{3}$. Mecanismos cuya configuración constitucional —a veces, pero no siempre, desarrollada por el legisladorseguramente no podía prever un contexto como el que se da no sólo en la España de nuestros días, sino también — con los lógicos matices- en otros regímenes democráticos parlamentarios ${ }^{4}$.

Pues bien: entre estos mecanismos, no cabe duda de que uno de los que ha suscitado mayor interés es el procedimiento de investidura previsto en el artículo 99 CE. Muchos son los aspectos del mismo que se han analizado: los plazos previstos (o no), las mayorías exigidas, las consecuencias de una falta de investidura... Y también, cómo no, la intervención del Monarca, prevista en los apartados 1 y 5 de dicho precepto constitucional. Concretamente, el examen de esta última cuestión no sólo ha merecido, en el número anterior de esta misma revista, un artículo ${ }^{5}$; sino que constituía una de las cinco preguntas planteadas a los expertos en la «Encuesta» de TRC, una de sus secciones más características y enriquecedoras desde sus orígenes, y que en dicho número se dedicaba al «Gobierno en funciones» ${ }^{6}$.

Como puede apreciarse en la formulación de dicha pregunta, uno de los argumentos utilizados en este debate es el referido a experiencia comparada de otras Monarquías parlamentarias, y al papel que los respectivos Monarcas desempeñan en ese proceso de designación de un Primer Ministro, o del Gobierno en su totalidad. Cabría precisar que, más concretamente (como denota el texto de la

elige nuestro presidente [del Gobierno]»: BAGEHOT, W.: La Constitución inglesa. Madrid, Centro de Estudios Políticos y Constitucionales, 2010, 1867, pp. 127-129. Sobre el procedimiento electoral como mecanismo de reducción de la complejidad social para crear «una voluntad política operativa», véase FERNÁNDEZ-MIRANDA CAMPOAMOR, C., y A., Sistema electoral, Partidos políticos y Parlamento. Madrid, Colex, 2008 ( $2^{\text {a }}$ ed.), p. 124.

3 Baste recordar aquí, a modo de ejemplo, los trabajos incluidos en el número anterior de esta misma Revista (Teoría y Realidad Constitucional [en adelante TRC], $\mathrm{n}^{\circ} 40,2017$ ); o en el ya citado $\mathrm{n}^{\circ} 109$ de la REDC, 2017.

4 Piénsese, a este respecto, en las dificultades que tras las elecciones de septiembre de 2017 ha atravesado la tradicionalmente estable Alemania para decantar una mayoría parlamentaria capaz de sostener un Gobierno. Circunstancias no tan diferentes a las que se han dado, en los últimos años, en otros países como Irlanda, Bélgica, Holanda o, incluso, en una Gran Bretaña cuyo Parlamento no ha contemplado mayorías absolutas unipartidistas en dos de las últimas tres legislaturas, obligando a fórmulas de coalición o pactos parlamentarios poco habituales en ese sistema.

5 PORRAS RAMÍREZ, J. Mª «La Corona y la propuesta de candidato a Presidente del Gobierno. Nuevas prácticas y viejas normas», TRC, nº 40, 2017, pp. 223-244.

6 Concretamente, la segunda de las preguntas planteadas a los siete expertos seleccionados era: «A la vista de las experiencias recientes, ¿Qué opinión nos puede dar sobre el papel del Rey en su propuesta al Congreso de los Diputados de candidato a Presidente del Gobierno? ¿ Cree que el refrendo por el Presidente del Congreso debe ser entendido de forma que no deje ningún margen de impulso al Rey? 'A mén de la consulta con los representantes designados por los Grupos políticos con representación parlamentaria, tendría sentido que el Rey tuviera la prerrogativa de escuchar a algún informador, en forma similar a como se opera en la monarquía holandesa?" (GARCÍA FERNÁNDEZ, J., GÓMEZ MONTORO, A. MONTILLA MARTOS, J.A., REVENGA SÁNCHEZ, M., REVIRIEGO PICÓN, F., RIDAURA MARTÍNEZ, M.J., SEIJAS VILLADANGOS, E., «Encuesta sobre el Gobierno en funciones», TRC, n citado, p. 12). 
pregunta formulada por TRC), los principales elementos de debate afectan al «margen de impulso» regio, así como —íntimamente ligado al anterior- a la posible previsión de otras figuras que operan en sistemas tradicionalmente utilizados como referente en esta materia, como es el caso del «informador» existente en los Países Bajos, o en Bélgica.

Así las cosas, y como tantas veces ocurre en el ámbito del Derecho Constitucional, no es posible tratar de responder a estas cuestiones sin situarlas en un contexto más amplio, relativo en este caso a los procedimientos de designación de los Jefes de Gobierno en los regímenes parlamentarios y, en particular, al papel que los Jefes de Estado (muy especialmente, los Monarcas) desempeñan en los mismos. A este aspecto trataremos de dedicar, siquiera muy brevemente, las siguientes páginas, centradas en primer lugar en la observación general y, sólo después, en los casos concretos.

\section{LA JEFATURA DE ESTADO EN EL NOMBRAMIENTO DE LOS GOBIERNOS PARLAMENTARIOS}

A nuestro juicio, no es posible considerar este preciso aspecto ignorando las tendencias que, con carácter muy general, afectan a la posición de la Jefatura del Estado en los sistemas parlamentarios, al margen incluso de su concreta configuración como Monarquía o República.

En efecto, es bien conocida la distinción acuñada por W. Bagehot entre «partes imponentes»y «partes eficientes» del sistema parlamentario británico? Aquellas «tienen mucha amplitud y no poco encanto; son muy antiguas y bastante venerables», y entre ellas «el papel de la reina... es de una utilidad incalculable», sin el cual el gobierno parlamentario inglés «no podría existir» ${ }^{8}$. Por el contrario, las «partes eficientes... tienen un movimiento muy sencillo y un sello más moderno»; en el caso inglés, su eficacia «reside... en la estrecha unión, en la fusión casi completa del poder ejecutivo y del poder legislativo», que permite al sistema, «si hace falta... obrar con más facilidad y mejor que ninguno de los [restantes] instrumentos políticos». Considerado en su conjunto, el sistema parlamentario (inglés) en «su esencia es fuerte con la fuerza toda que le presta la sencillez de los procedimientos en la época moderna; su exterior es majestuoso como lo era el carácter gótico de una época más imponente»?

Pues bien: no parece descabellado afirmar que si los nuevos tiempos no son buenos para la lírica, tampoco lo son para los elementos «góticos», «venerables»o

7 La Constitución inglesa, cit., pp. 5-6 y 10 (edición a cargo de J. VARELA SUANZES-CARPEGNA, que recoge íntegramente la traducción española original que hiciera, en 1902, A. Posada). En el original inglés, Bagehot hablaba de dignified y efficient parts (The English Constitution. Londres, Fontana Press, 1993, p. 63).

8 La Constitución..., cit., pp. 10 y 47.

9 Ibidem, pp. 10-11. 
«majestuosos» del sistema político. En realidad la primacía del elemento eficiente no es sino la lógica consecuencia del triunfo del principio democrático: la democratización del poder ha producido la hegemonía del parlamentarismo monista, que entre otros aspectos se manifiesta en el «desvanecimiento» de los Jefes de Estado $^{10}$. Un desvanecimiento que alude «a la idea de que el Jefe de Estado ha sido privado de la autoridad y de la potestad gubernamental», y que constituye una tendencia general, pero «relativa, ya que ha de distinguirse» dicho desvanecimiento «en el régimen político» $\mathrm{y}$ «en el régimen constitucional».

En efecto, «la diferenciación entre los Monarcas, los Presidentes elegidos por un colegio restringido o... [aquellos elegidos] por sufragio universal» no resulta en la práctica tan clara como cabría pensar. A ello contribuyen «dos tipos de razones»: en primer lugar, el que «muchos textos constitucionales siguen siendo dualistas» formalmente, y el «desvanecimiento resulta de la práctica, lo que suscita interrogantes» sobre la eventual reactivación de los textos; a continuación, porque «en la mayor parte de los países el Jefe de Estado, pese a no ser ya una autoridad de gobierno, conserva un papel no desdeñable» ${ }^{11}$.

Por consiguiente, el estudio del papel de la Jefatura del Estado en los modelos parlamentarios, y en particular en las Monarquías, exige superar las apariencias, y los textos. «Pocas Constituciones tienen en efecto una presentación puramente monista»: entre las Monarquías, Suecia y España ya no atribuyen a sus Monarcas la titularidad nominal del poder ejecutivo, tampoco lo hacen Repúblicas como Alemania, Grecia, Italia o Irlanda... Pero en la mayor parte de los demás casos, tanto las Monarquías (Noruega, Luxemburgo, Bélgica, Holanda, Dinamarca) como las Repúblicas (Finlandia, Islandia, Austria, Francia, Portugal...) atribuyen a sus Jefes de Estado importantes poderes constitucionales configurando así sistemas dualistas, al menos en apariencia.

En todo caso, la tendencia natural de las Monarquías hacia el monismo implica que «los Monarcas apenas pueden permitirse incursión alguna en el terreno político»: sobre ellos pesa una «red cruzada de límites» derivados de «la Constitución y las convenciones que la acompañan», que les deja «muy pocas competencias de ejercicio verdaderamente discrecional», cuyo ejercicio además depende de ciertas variables políticas ${ }^{12}$.

Y uno de los ámbitos en que tradicionalmente se ha considerado factible la posible intervención regia es en el nombramiento del Jefe de Gobierno. Una competencia considerada «típicamente arbitral», si bien «la existencia de un verdadero arbitraje» depende de circunstancias políticas como el sistema de partidos y el equilibrio entre los mismos. De cualquier modo, «el arbitraje, que consiste

10 Utilizamos esta expresión para traducir la de «effacement des chefs d'Etat» que utlizan C. GREWE y H. RUIZ-FABRI (Droits constitutionnels européens. París, PUF, 1995, pp. 482 y sigs.)

11 Ibidem. $225-226$

12 Ibidem, p. 493. En el mismo sentido, J.M. PORRAS NADALES, «La Corona...», ob. cit., pp. 
en ejercer su propio criterio, supone por naturaleza una situación de conflicto»y se concibe como algo excepcional ${ }^{13}$.

En el caso español, como es lógico, la cuestión también se ha planteado. Inicialmente, algunos autores como I. De Otto apuntaron la posible existencia de un poder de reserva regio que, con carácter supletorio, permitiría al Rey «actuar autónomamente en caso necesario, para evitar el bloqueo institucional», de modo que podría «adoptar una iniciativa propia que, al menos, pusiese en marcha el procedimiento designatorio»; pero en general se ha impuesto la idea de que «la exigencia de determinadas mayorías implica una limitación obvia a toda posible discrecionalidad regia en este terreno» ${ }^{14}$.

Hoy día, pues, la posible naturaleza «arbitral» de la facultad regia de proponer al Congreso una candidatura a la Presidencia del Gobierno parece mayoritariamente descartada por la doctrina. En expresión rotunda recientemente recogida en estas mismas páginas, «no estamos... ante una expresión de Poder Arbitral y Moderador: no hay nada que arbitrar ni moderar porque ello comportaría otorgar un margen discrecional al Rey que no puede poseer ${ }^{15}$. En definitiva, el papel del Jefe del Estado no debe «ir más allá de su carácter meramente simbólico y protocolario», limitándose a «la mera ratificación de los acuerdos alcanzados (o, en su caso, no alcanzados)... por los verdaderos protagonistas, los grupos políticos con representación parlamentaria» ${ }^{16}$.

En el contexto de este debate acerca de la naturaleza y alcance de la competencia regia no resulta extraño que la doctrina haya prestado atención a figuras como la del «formador» $\mathrm{o}$ «informador» presentes en otros sistemas parlamentarios. Figuras que, al intervenir en el proceso de propuesta y nombramiento formalmente atribuido al Rey, pueden afectar a su papel y, en particular, a su «margen de impulso», por volver a utilizar la expresión ya observada. Y sobre cuya significación y eficacia existen dudas más que razonables, como confirma el claro escepticismo de la mayor parte de los expertos consultados en la reiterada «Encuesta» ante la posibilidad —en principio, perfectamente posible — de importar esta solución para el régimen constitucional español ${ }^{17}$. De cualquier modo, ese interés puede justificar un estudio algo más profundo de dichas figuras, a las que trataremos pues de dedicar nuestra atención.

13 Ibidem, pp. 495-496.

14 BAR CENDÓN, A., "Artículo 99», en ALZAGA VILLAAMIL, O., (Dir.), Comentarios a la Constitución española de 1978, vol. VIII, pp. 282-283.

15 J. GARCÍA FERNÁNDEZ, en la ya citada «Encuesta...» (TRC, n 40, p. 31). El Rey «tiene algo de notario que da fe del panorama parlamentario a partir de la información proporcionada» por los grupos políticos en la fase de consultas. En términos muy similares, véase PORRAS NADALES, J.M., «La Corona...», ob. cit., passim, esp. pp. 233-234 y 241-242.

16 REVIRIEGO PICÓN, F., Ibidem, p. 37

17 Así se expresan J. GARCÍA FERNÁNDEZ (p. 32: «una figura extraña a nuestra práctica»); Á. J. GÓMEZ MONTORO (p. 33: «dudo mucho de su eficacia... incluso podría generar mayor ruido mediático»); M. REVENGA SÁNCHEZ (p. 36: «no añadiría ninguna mejora sustancial»); $\mathbf{M}^{a}$ E. SEIJAS VILLADANGOS (p. 43: «sin una cultura política y constitucional previa, los visos de éxito de la importación de estas prácticas quedarían muy minorados»). 


\section{LOS COLABORADORES DE LA CORONA EN LA SELECCIÓN DE LOS PRIMEROS MINISTROS: PAÍSES BAJOS Y BÉLGICA}

Sin duda, el ejemplo más conocido en esta materia es el que proporciona Bélgica. Pero, como es sabido, no es el único: también en los Países Bajos, la figura del «informador» (informateur, siempre en francés) aparece como esencial en el proceso de formación del Gobierno. Ambos sistemas, como es lógico dada su proximidad histórica, parten de postulados similares y, en particular, de unos textos constitucionales que en esta concreta materia se limitan a señalar que el Rey nombra a los ministros, manteniendo pues formalmente la tradicional competencia regia ${ }^{18}$. A partir de ahí, ninguna de ellas regula el procedimiento de formación del Gobierno, que por consiguiente se basa casi exclusivamente en convenciones y reglas no escritas.

\section{Breve referencia al reformado modelo holandés}

Ahora bien: en fecha relativamente reciente, una reforma de esta materia en Holanda ha supuesto una profunda modificación en su significado político e institucional. Concretamente, en marzo de 2012 la Cámara Baja modificó su Reglamento para suprimir la intervención regia en el proceso de elección del Primer Ministro y formación del Gobierno, recabando para sí la iniciativa de dicho proceso mediante la designación del formador y, si fuera preciso, del (o de los) informador(es). De este modo, la reforma redujo el «margen de impulso» regio, inscribiéndose pues en la citada - y lógica — tendencia a aislar al Monarca de los procesos políticos, y alejándose del modelo belga.

En todo caso, y al margen de esa significación política, ni antes ni después de la reforma el proceso ha destacado por su agilidad. Algo que no debería sorprender en un país cuyas elecciones no han producido ninguna mayoría absoluta parlamentaria desde el siglo XIX, y obligado por tanto a componer coaliciones de gobierno no siempre fáciles. De hecho, según los datos que aporta la Cámara Baja holandesa, «la duración media del proceso de formación de Gobierno desde 1946 ha sido de 89.5 días» ${ }^{19}$. Y este resultado no parece depender de la mayor o menor intervención del Rey, sino de la fragmentación parlamentaria: en las últimas elecciones del 15 de marzo de 2017 accedieron al Parlamento trece formaciones distintas, de las que solo una supera - por poco- el $20 \%$ de los votos (y escaños), y nueve no llegan al 10 $\%$. No extraña, pues, que fueran necesarios 225 días de negociaciones para formar un nuevo Gobierno, acabando así con el record anterior (establecido en 1977) de $208^{20}$.

18 Art. 43 de la Constitución holandesa: «El Primer Ministro y el resto de los Ministros son nombrados y revocados por Decreto Real». Artículo 96 de la Constitución belga: «El Rey nombra y revoca a sus Ministros».

19 Véase https://www.houseofrepresentatives.nl/formation-process.

20 Unas consideraciones algo más detalladas sobre el funcionamiento de este proceso en los Países Bajos pueden encontrarse en la citada aportación de $\mathrm{M}^{\mathrm{a}} \mathrm{E}$. SEIJAS VILLADANGOS a la misma «Encuesta...», 


\section{El modelo de Bélgica}

Este modelo fue ya objeto de otro estudio que hicimos en esta misma Revista, hace ahora diez años, con ocasión de la crisis planteada en ese país... precisamente al hilo de las dificultades para formar una mayoría parlamentaria y de gobierno $^{21}$. Un tipo de dificultades que por entonces parecían muy lejanas e improbables en España, apariencia que los hechos posteriores se han encargado de desmentir. Y que posteriormente se han repetido, e incluso agravado, también en Bélgica, lo cual — dicho sea de paso- permite apuntar ya (o confirmar, si consideramos el ejemplo holandés) que la intervención de tales figuras no asegura per se un proceso fácil y fluido de designación del Gobierno. Pero más que la eficacia, lo que ahora nos interesa es, sobre todo, la significación política e institucional de este modelo y, en particular, su incidencia sobre el eventual «margen de impulso» de la Corona en este proceso.

Obviamente, para apreciar el funcionamiento, los efectos y la significación del modelo es preciso examinar el sistema en que se inscribe, y las reglas que lo condicionan. Reglas, como trataremos de exponer, muy heterogéneas y que combinan disposiciones constitucionales claramente anacrónicas con otras generadas por una práctica política que ha permitido, a la vez, la pervivencia y la evolución de aquellas, generando a su vez nuevas cuestiones, como pasamos a observar.

\section{A) Reglas constitucionales}

Se ha dicho, seguramente con razón, que la «Constitución belga está buscando desesperadamente una Nación» ${ }^{22}$. Y tal vez ahí quepa encontrar la causa de una regulación constitucional que ha permanecido, en este punto y como ya se ha apuntado antes, esencialmente inalterada desde el primer tercio del siglo XIX.

En efecto, es bien sabido que Bélgica adquirió su independencia del Reino Unido de los Países Bajos en 1830. Inmediatamente, el 7 de febrero de 1831, se dotó de una Constitución generalmente considerada como una de las más progresistas de la época, y que estuvo formalmente vigente hasta que, el 17 de febrero

donde — curiosamente, o no— se apunta que «la parlamentarización de ese proceso y su intrínseca politización... ha tensionado el papel del Rey», hasta el punto de que "parece añorarse el protagonismo regio» (pp. 41-42). La revista Político ofrece (en https:/www.politico.eu/article/dutch-government-coalition-talks-formation-election-2017-netherlands-mark-rutte/) una crónica minuciosa de la última experiencia de marzo-octubre 2017, que exigió la intervención sucesiva de tres informadores (la primera de los cuales fue designada en dos ocasiones, porque renunció tras un primer intento fallido), pertenecientes a dos partidos diferentes, para conseguir una coalición formada por cuatro partidos, con una mayoría de un solo escaño.

21 Véase SÁNCHEZ NAVARRO, Á.: «Actualidad política y constitucional belga (2007-2008): apuntes para entender una crisis», TRC, $\mathrm{n}^{\circ} .22,2008$, especialmente, pp. 386-389.

22 POPELIER, P., LEMMENS, K., The Constitution of Belgium. A contextual Analysis; Hart, Oxford and Portland, 2015, p. vi. 
de 1994, fue sustituida por la actual, que es «en rigor... un texto refundido de la Constitución originaria de 1831 y las numerosas reformas posteriores $»^{23}$.

Esta continuidad explica, por una parte, la pervivencia de disposiciones claramente arcaicas, como las que prescriben que «el Poder Legislativo Federal será ejercido conjuntamente por el Rey, la Cámara de Representantes y el Senado»; o que «corresponde al Rey el Poder Ejecutivo Federal» (artículos 36 y 37, respectivamente; vide también el artículo 74). Pero resulta, por otra, especialmente llamativa por cuanto el «nuevo» texto de 1994 ha sufrido, a su vez, numerosas (incluso, numerosísimas) reformas desde su entrada en vigor ${ }^{24}$. Reformas que responden normalmente a «difíciles compromisos políticos entre los principales grupos lingüísticos» existentes en Bélgica, pero carecen de un «objetivo claro» o de un «proyecto institucional global», respondiendo así a un planteamiento absolutamente fragmentario (patchwork approach ${ }^{25}$ ).

De este modo, las diversas reformas constitucionales apenas han afectado a la regulación de la Corona ${ }^{26}$. Y así, junto a preceptos como los anteriormente mencionados, el artículo 96 dispone que «El Rey nombra y revoca a sus Ministros», reproduciendo literalmente el artículo 65 del texto de 1831.

Este poder de nombramiento (matizado por un apartado segundo introducido en 1993, que prevé el supuesto de pérdida de confianza parlamentaria del Primer Ministro) se ve, ciertamente, sometido a ciertas reglas, a veces tradicionales —más o menos adaptadas—, y otras más recientes. Así, por ejemplo, entre las primeras han de citarse aquellas según las cuales «sólo los belgas podrán ser Ministros», excluyéndose a todos los miembros de la familia real ${ }^{27}$. Mientras que las segundas incluyen aquellas que prescriben que «el Consejo de Ministros contará como máximo con quince miembros» (artículo 99, párrafo ${ }^{028}$ ); o las que prevén que «con excepción, en su caso, del Primer Ministro... contará con tantos miembros de expresión francesa como de expresión neerlandesa» (99, párr. $2^{\circ}$ ); o exigen que «cuente con personas de diferente sexo» (artículo $11{b i s^{29}}^{29}$.

De cualquier modo, y al margen de esas condiciones, lo cierto es que la fórmula adoptada por el artículo 96 de la Constitución otorga al Rey un poder de

23 DARANAS PELÁEZ, M., en RUBiO LLORENTE, F., DARANAS PELÁEZ, M., (Eds.): Constituciones de los Estados de la Unión Europea. Barcelona, Ariel, 1997, p. 113.

24 Así, el portal oficial del Senado belga enumera, desde 1994 hasta 2014, 27 reformas que afectan a 76 artículos (42 en la última, de 6 enero de 2014: https://www.senate.be/www/?MIval=/ index_senate\&MENUID $=14150 \& \mathrm{LANG}=\mathrm{fr})$.

25 La expresión, y las otras citas, proceden de POPELIER, P., LEMMENS, K., The Constitution..., ob. cit., pp. V y 16. Sobre los difíciles equilibrios lingüísticos, regionales, institucionales y constitucionales, véase nuestro estudio anteriormente citado ( «Actualidad política y constitucional belga...»).

26 En rigor, «del Rey» (Du Roi: Capítulo III, y especialmente su Sección primera).

27 Artículos 97 y 98 C.B., que recogen — con algún matiz, en el primer caso- los anteriores artículos 86 y 87 , intactos desde 1831.

28 Una previsión que M. DARANAS considera «completamente nueva y excepcional en el Derecho comparado» (op. cit., p. 125).

29 Artículo introducido por la reforma de 21 de febrero de 2002. 
considerable amplitud. Antes de la revisión constitucional de 1994 (que, recordémoslo, no modificó este precepto), un comentario al texto constitucional belga subrayaba que dicha regla «reserva al Rey [actuando con el correspondiente refrendol la posibilidad de componer los Gobiernos, de aceptar y de rechazar su dimisión, de designar a los Ministros, de aceptar y de rechazar su dimisión individual, de destituirlos» ${ }^{30}$. Con posterioridad, sigue afirmándose que «la autoridad investida por la Constitución de la responsabilidad de designar a los Ministros es, indiscutiblemente, el Rey. Él, y sólo él, tiene derecho a nombrarlos», actuando «como autoridad perteneciente al poder ejecutivo federal, en el sentido del artículo $37 \mathrm{C} . »^{31}$. Y, en consecuencia, «en las fases de formación de Gobierno... el Rey dispone de un margen de maniobra mucho más importante que el que se le reserva habitualmente ${ }^{32}$, ya que «en cierta medida dirige los debates como un observador implicado $»^{33}$.

En todo caso, es obvio que estas reglas constitucionales expresas deben completarse con otras implícitas en el sistema. Entre ellas, la primera parece obvia: en un sistema parlamentario, el Gobierno debe gozar de la confianza de las Cámaras (algo expresamente recogido ahora por la regulación de la moción de censura y de la cuestión de confianza en el artículo 96, párr. $2^{\circ}$ C.B.). Ello sitúa el foco de atención en el sistema de partidos y en la necesaria, y difícil, formación de mayorías en un Parlamento - como el holandés - muy fragmentado, como veremos más adelante. A pesar de lo cual, y posiblemente por los antecedentes existentes en Bélgica, la regla de que la nominación del Gobierno no «está sometida al asentimiento o a la ratificación de las Cámaras legislativas» abre la puerta a consideraciones sobre la posibilidad de «Gobiernos minoritarios». Así, se ha señalado que «la confianza o desconfianza de la[s] Cámara[s]... no se presume, se verifica», de modo que «nada impide al Rey componer un Gobierno que no goce de un respaldo suficiente de diputados... Este Gobierno tendrá entonces su oportunidad», si bien la expresa negación de la confianza parlamentaria provocará inevitablemente su caída ${ }^{34}$.

A la vista de cuanto se ha expuesto, resulta claro que la Constitución belga mantiene formalmente el esquema tradicional del siglo XIX, con un ejecutivo bicéfalo formado por el Rey y el Gobierno. Un esquema que, como es natural, sólo ha podido mantenerse formalmente vigente gracias a una profunda relectura de sus términos, en una evolución que «no es excepcional como tal», pero resulta llamativa porque «se ha producido sin ninguna reforma constitucional» ${ }^{35}$, y

30 DELPÉRÉE, F., JONGEN, F., Quelle revisión constitutionnelle? Louvain-la-Neuve- Bruxelles, Academia-Bruylant, 1987, p. 113 (las cursivas han sido añadidas). 410-411.

31 DELPÉRÉE, F., Le droit constitutionnel de la Belgique. Bruylant-LGDJ, Bruxelles-Paris, 2000, pp.

32 UYTTENDAELE, M., Précis de droit constitutionnel Belge. Regards sur un système institutionnel paradoxal. Bruylant, Bruxelles, 2005 ( $3^{\mathrm{e} e}$ éd.), p. 416.

33 Participating observer: POPELIER, P., LEMMENS, K., ob. cit., p. 146.

34 DELPEREE, F., Le droit constitutionnel..., ob. cit., pp. 411 y 414-415.

35 POPELIER, P., LEMMENS, K., ob. cit., p. 148. 
gracias a la adopción de ciertas prácticas que han sido convencionalmente asumidas hasta conformar un auténtico «ritual» ${ }^{36}$. A ello dedicaremos el siguiente epígrafe.

\section{B) Convenciones politicas}

Así pues, la complejidad del marco institucional belga y la coherente evolución de su sistema de partidos, al que habremos de aludir más tarde ${ }^{37}$ constituyen factores que dificultan notablemente la formación de un Gobierno federal. Es preciso conformar coaliciones que combinen equilibrios diversos (lingüísticos y partidistas), para lo cual se han desarrollado, como en Holanda, ciertas prácticas políticas generalmente respetadas y que, en ocasiones, resultan, como mínimo, sorprendentes.

Es preciso insistir en que se habla aquí de prácticas dirigidas a facilitar la elección regia, en las que no cabe apreciar la existencia de una auténtica «convención constitucional, sino simplemente una práctica que se recomienda, por regla general» y por razones de utilidad, «respetar» ${ }^{38}$. Y que afectan a un período en el cual «el Rey desempeña un papel determinante. Este es el único momento en el que está en condiciones de influir directamente sobre la vida política nacional, independientemente de la voluntad del Gobierno. En esta ocasión, él elige las personas encargadas de llevar a cabo las negociaciones relativas a la formación del Gobierno. Estas designaciones son anunciadas por un comunicado de palacio, y no constituyen el objeto de un acto refrendado por un ministro, al menos en el momento en que se deciden. Pese a lo cual, formalmente, los ministros dimisionarios asumen la responsabilidad política de las mismas» ${ }^{39}$.

El proceso se inicia al día siguiente de las elecciones generales federales, cuando el Primer Ministro presenta al Rey la dimisión de su Gobierno, siendo encargado de seguir en funciones hasta la formación de otro nuevo. Se abre, a continuación, un período de consultas, presidido por el principio de que «el Rey es libre» en las mismas, pero durante el cual el Rey recibe — «según la tradición protocolaria»— a diversas personalidades, como el Primer Ministro dimisionario, los Presidentes de

36 DELPÉRÉE, F., op.cit., citando a A. Molitor, a quien sigue en su descripción del proceso (pp. 420423). Vide también UYTTENDAELE, M., Précis..., ob. cit., pp. 417 y ss. Una breve exposición de estas prácticas puede encontrarse, asimismo, en el sitio web institucional belga (https://www.belgium.be/fr/la_belgique/ pouvoirs_publics/autorites_federales/gouvernement_federal/formation_gouvernement).

37 Sobre este aspecto, véase SÁNCHEZ NAVARRO, A., «Sistemas de partidos e integración política: de Cataluña a Bélgica», en LÓPEZ GUERRA, L., GARCÍA RUIZ, J.L., GARCÍA FERNÁNDEZ, F.J., (Dirs.), Constitución y desarrollo político. Estudios en homenaje al Profesor Jorge de Esteban, Valencia, Tirant lo Blanch, 2012, pp. 1531 y sigs. (especialmente, el epígrafe dedicado a «El sistema de partidos en Bélgica: la quiebra de un proyecto nacional»).

38 DELPÉRÉE, F., ob. cit., p. 420.

39 UYTTENDAELE, M., ob. cit., p. 417. 
ambas Cámaras, los líderes de los principales partidos del país, así como a los responsables de organizaciones económicas y profesionales ${ }^{40}$.

Tras estas consultas, el Rey puede optar por designar a un formador (formateur), encargándole directamente la formación de un nuevo Gobierno. Sin embargo, más frecuentemente, y debido a la falta de mayorías claras, se ve impulsado a desarrollar algunos pasos intermedios, lo que suele traducirse en la designación de un informador (informateur ${ }^{41}$ ). Éste, cuya designación tampoco es absolutamente libre y ha de tener en cuenta los condicionantes existentes en cada momento, suele ser un responsable político experimentado encargado de profundizar en la labor «exploratoria» iniciada por el Jefe del Estado. A tal fin debe examinar «todas las fórmulas de gobierno posibles», remitiendo al Rey su informe, que puede consistir en «un documento escrito que sintetiza sus conversaciones», aconsejándole en su caso sobre la designación de un formador.

Ahora bien: en los últimos años, y esencialmente desde 2007, la progresiva fragmentación parlamentaria está dificultando notablemente la formación de mayorías, lo que se ha traducido en una «multiplicación de consejeros regios, que exceden claramente el dúo informador-formador, a fin de desbloquear la situación política» ${ }^{42}$. De este modo, en un tercer momento, el Rey puede designar a uno o varios mediadores (médiateurs), con una misión a medio camino entre la mera información y el impulso para aproximar posturas. Incluso se prevé la posibilidad de recurrir a un negociador (négociateur), abiertamente orientado a posibilitar acuerdos sobre puntos concretos.

En caso de tener éxito, en uno u otro momento, el proceso finaliza pues con la designación de un formador, que normalmente se convertirá en el nuevo Primer Ministro... aunque la práctica política ofrezca algunas excepciones, en las que esta figura ha debido dejar paso, en el último momento y por razones diversas, a otro líder. Lo cual no implica que todo esté hecho: el formador debe establecer, en primer lugar, una fórmula de coalición; a continuación, un programa de gobierno; $\mathrm{y}$, finalmente, un equipo para llevarlo a cabo. Todo lo cual exige «procedimientos a menudo largos y laboriosos», y «cada vez más formalizados» ${ }^{43}$, en los cuales el papel del Jefe del Estado tiende, lógicamente, a disminuir: «los políticos asumen el liderazgo e informan al Rey, el cual sólo intervendrá en momentos de crisis o cuando las negociaciones se encuentren bloqueadas» ${ }^{44}$.

Como no podría ser de otra manera, todo este proceso, y en particular el protagonismo del Rey a la hora de designar a estas figuras intermediarias (algo que

40 El mismo autor subraya que, desde 1991 y en uso de su libertad de organizar sus consultas, ni Balduino I ni Alberto II han recibido a los representantes de los partidos radicales e independentistas (Front National, Vlaams Blok o Vlaams Belang: p. 417).

41 Figura aparecida, por vez primera, en 1935 (SENELLE, R., La Constitución belga comentada. Bruselas, Ministerio de Asuntos Extranjeros, 1974, p. 229).

42 POPELIER, P., LEMMENS, K., ob. cit., pp. 145-146.

43 DELPÉRÉE, F., op. cit., p. 422.

44 POPELIER, P., LEMMENS, K., ob. cit., p. 147. 
hace, dentro lógicamente de los condicionantes derivados de la composición parlamentaria, «libremente, asesorado por sus consejeros y su jefe de gabinete» ${ }^{45}$ ), ha sido ha sido ampliamente debatido. Ciertamente, el papel regio se reduce cuando se desbloquea el proceso, puesto que la designación de los miembros del Gobierno corresponde exclusivamente a cada partido. Pero aún se apunta que no hace demasiado tiempo el Rey Balduino se opuso al nombramiento de algunos candidatos como ministros o a algún reparto de carteras ${ }^{46}$.

En todo caso, esta discusión seguramente perviva en el futuro aunque, como se ha señalado, ello dependerá en gran parte de la actitud del Rey Felipe. Si éste mantiene la actitud institucional que ya caracterizó a su padre, el Rey Alberto, y deja por tanto que sean los políticos quienes protagonicen el debate político, institucional y constitucional, es de esperar «una suave evolución hacia una Monarquía más modesta. En el caso de que se resista a dicha evolución, pueden surgir fuertes y penosas tensiones entre la élite política y el Rey» ${ }^{47}$.

\section{C) La aplicación práctica del modelo}

Evidentemente, y como se ha subrayado con anterioridad, el funcionamiento de este modelo ha de situarse en el contexto de un sistema parlamentario, como el belga, donde la formación de mayorías resulta cada vez más difícil, a causa de un sistema de partidos crecientemente fragmentado. En particular, en las últimas décadas las tensiones nacionalistas han afectado profundamente a la evolución del sistema de partidos, hasta el punto de que podría ponerse en duda si éste ha dejado de cumplir su función «agregativa» o «integradora» para convertirse en un elemento de desintegración, de tal intensidad que llega a cuestionar seriamente las posibilidades del Estado belga como proyecto político único.

En efecto, desde el siglo XIX hasta la década de los 1960 el sistema político belga estuvo básicamente dominado por unos partidos que se correspondían con las principales corrientes ideológicas existentes en el continente. Católicos (luego, democristianos, organizados desde la II Guerra Mundial en el PSC/CVP), liberales (PVV/PLP) y socialistas (PSB/BSP) constituyeron durante todo este tiempo Gobiernos, ya monocolores (sobre todo, democristianos) o ya, más frecuentemente, de coalición, según fórmulas diversas. Así, a inicios de la década de los cincuenta del siglo pasado, Maurice Duverger consideraba al sistema de partidos belga como un sistema unitario, multipartidista moderado (tripartidista), llegando incluso a compararlo en algún momento al británico ${ }^{48}$. Es más: el sistema

45 Ibidem.

46 Ibidem, p. 148.

47 Ibidem.

48 «Entre 1918 y 1935 era imposible hablar del bipartidismo inglés, ya que el pueblo británico estaba repartido realmente en tres grandes partidos. Hablar de ello hoy puede parecer arbitrario, sobre todo si se 
belga llega a proponerse como ejemplo de que «la representación proporcional actúa... [de modo que] opiniones fuertemente arraigadas localmente tienden a extenderse al plano nacional» $y$, por tanto, «a reforzar la unidad nacional»: es lo que denomina «una especie de nacionalización progresiva de las opiniones y de los partidos», que «en Bélgica atenúa... la rivalidad de los flamencos y los valones, que correría el riesgo de ser exasperada por una vuelta al sistema mayoritario», el cual acentuaría «el carácter flamenquista del Partido Católico y la tendencia valonizante de los socialistas» transformando a ambos «en partidos autonomistas» ${ }^{49}$.

Dos décadas más tarde, Giovanni Sartori consideraba a Bélgica como un sistema de pluralismo moderado, y baja fragmentación, aunque ya subrayaba su evolución: «durante por lo menos setenta años... [Bélgica] es el ejemplo más duradero y claro de un formato de tres partidos... Pero a partir de 1965 la pauta se hace más complicada. Es cierto que el grupo flamenco... ya era muy visible en 1939, pero hasta la segunda mitad del decenio de 1960 la división étnica y la crisis lingüística no habían irrumpido en la liza política. Desde 1968 no sólo ha aparecido el Partido Nacionalista Flamenco (Volksunie) como partido considerable, sino que una reacción francófona (valones y Bruselas) ha entrado en liza con una fuerza casi igual $¿$ Estamos presenciando, pues, una transición de un formato de tres partidos a otro de cinco...?» En todo caso, «hasta la fecha, los católicos, los socialistas y los liberales siguen jugando la partida gubernamental entre sí, exactamente igual que venían haciendo hasta ahora», por lo que «desde 1919... Bélgica ha estado gobernada casi exclusivamente por coaliciones bipartidistas alternativas». Lo cual no quiere decir «que la comunidad política belga vaya a, o pueda, perdurar en su forma actual... Hasta ahora, el conflicto lingüístico $-\mathrm{y}$ la ascendencia creciente e inevitable de la población flamenca- han producido una reestructuración bicéfala de los tres partidos tradicionales... Resulta difícil prever si estos arreglos van a durar, si al final resultará inevitable una solución federal y/o si un sistema de partidos más fragmentado acabará por destruir el modelo tripartito» ${ }^{50}$.

Casi al mismo tiempo, en términos similares, Dieter Nohlen resaltaba el equilibrio político garantizado por los tres grandes partidos belgas, si bien alertaba de que «desde comienzos de los años 60» se multiplicaron las «crisis de gobierno», en parte por la «cada vez mayor importancia [de] la oposición entre flamencos y valones», contemplada ya como «una amenaza grave para la unidad del país y para el sistema político actual» al determinar «un corte longitudinal en los partidos». En consecuencia, advertía este autor, «será necesario esperar

considera a Bélgica como un régimen de multipartidismo, en el que la influencia liberal es apenas más poderosa que en Inglaterra: sólo el sistema electoral asegura al partido una representación parlamentaria sensiblemente más fuerte» (DUVERGER, M., Los partidos políticos. México, Fondo de Cultura Económica, $1987\left[10^{2}\right.$ reimpr. española; $1^{\mathrm{a}}$ ed. francesa, 1951], p. 236).

49 Ibidem, p. 409 (las cursivas han sido añadidas).

50 SARTORI, G., Partidos y sistemas de partidos, I. Madrid, Alianza Editorial, 1987 (1ª reimpr.), pp. 163,219 y ss, 232-234 (cursivas añadidas). 
para ver en qué medida la federalización influye en los partidos y en la estructura del sistema de partidos $»^{51}$.

Cuatro décadas después, la respuesta a esa interrogante parece clara: «las controversias entre ambas comunidades lingüísticas y la comunitarización de la lucha política mediante el nacimiento de partidos etno-lingüísticos en cada una de las comunidades erosionando el apoyo electoral de los partidos tradicionales unitarios belgas, dieron lugar... a un conflicto de carácter cultural y económico entre dos comunidades enfrentadas ${ }^{52}$, que trató de encauzarse mediante las cuatro profundas «reformas del Estado» aprobadas entre 1970 y 1993.

En el concreto ámbito de los partidos políticos, este proceso de diferenciación etno-lingüística acabó por provocar la escisión de los tres grandes partidos tradicionales además de permitir el auge de grupos — generalmente, minoritarios, pero no marginales - vinculados a una de las comunidades. Por consiguiente, el sistema de partidos belga resulta hoy, en gran parte, de una mera yuxtaposición de dos subsistemas, el francófono y el flamenco. Ello, unido a la proporcionalidad del sistema electoral, ha provocado una creciente dificultad para conseguir mayorías de gobierno formadas, normalmente tras largos procesos de negociación, por cinco, seis o más partidos... y de escasa estabilidad.

En efecto, la observación de las últimas legislaturas belgas ofrece un primer dato reseñable: no han llegado agotar su período de mandato ${ }^{53}$. Algo que no parece extraño, dados los resultados electorales registrados en la última década. Así, las de 10 de junio de 2007 distribuyeron los 150 escaños de la Cámara de Representantes entre once listas: la mayor de ellas, una coalición formada, a su vez, por los democristianos flamencos $(\mathrm{C}-\mathrm{D} \& \mathrm{~V})$ y un grupo nacionalista, Nueva Alianza Flamenca (N-VA) logró apenas un 18'5\% de los votos. Las otras diez obtuvieron tan sólo entre un 12'5 \% y un 1'97 \%, lo que da idea de la dificultad de configurar una mayoría absoluta ${ }^{54}$.

Tres años después, el 13 de junio de 2010, la ruptura de esa coalición mayoritaria acentuó la fragmentación: la lista ganadora (N-VA) alcanzó solo un 17’40 \% de los votos, y otras once oscilaron entre el $13^{\prime} 70 \%$ de los Socialistas francófonos (PS) y el 1'29\% de una nueva formación de derecha francófona, el Parti Populaire ${ }^{55}$.

51 NOHLEN, D., Sistemas electorales del mundo. Madrid, CEC, 1981, páginas 392-397.

52 GARMENDIA MADARIAGA, A., La posible plasmación de la teoría del tercer miembro del Estado federal en el ordenamiento jurídico español. Madrid, CEC, 2011, páginas 8 y 9 (cursivas añadidas).

53 «Los miembros de la Cámara de Representantes son elegidos por cinco años» (art. 65 de la Constitución belga).

$54 \mathrm{http}: / /$ elections2007.belgium.be/fr/cha/results/results_graph_etop.html. En cuanto al Senado, baste señalar aquí que los 40 senadores elegidos directamente pertenecían a esas mismas once formaciones. A ellos habían de unirse otros 34 senadores: 21 designados por los Parlamentos de las Comunidades, 10 cooptados por los propios senadores, y los senadores de iure (en ese momento, tres): «Los hijos del Rey o, en su defecto, los descendientes belgas de la rama de la familia real llamada a reinar, serán senadores natos al cumplir los dieciocho años de edad, si bien no podrán votar hasta cumplir los veintiún años, y no serán contados para el cómputo del quórum de asistencia» (artículo 72 C.B.).

55 http://elections2010.belgium.be/fr/cha/results/results_graph_CKR00000.html. 
Cuatro años más tarde, el 25 de mayo de 2014, el no de partidos parlamentarios ascendió hasta 13. El mayor (nuevamente, el N-VA) lograba alcanzar el 20 '26 \%; el último que accedió a la Cámara (también, de nuevo, el Parti Populaire), el 1'52\%. Entre uno y otro, cinco formaciones rondan el $10 \%$ (del 11'67 del PS al 8'83 del sp.a); y otras seis reúnen entre el 1'8 y el 5'3 \%

En todo caso, la significación de esos datos se refuerza al considerar que, entre 2007 y 2014 no había en la Cámara ningún partido de ámbito nacional belga: sólo existían partidos flamencos ${ }^{57}$ o francófonos ${ }^{58}$, cada uno de ellos con apoyos casi exclusivamente procedentes de su comunidad lingüística ${ }^{59}$. Sólo en 2014 el «Partido del Trabajo de Bélgica», un pequeño partido de filiación comunista que opera como partido único de ámbito belga (aunque, debido a la organización electoral, concurre con la doble denominación de PVDA+/PTB-Go!) ha logrado acceder a la Cámara, logrando 2 escaños (ambos en la zona francófona), y algo menos del $4 \%$ de los votos en el total nacional.

Obviamente, este panorama constituye un serio obstáculo para la formación de gobiernos estables y capaces de integrar proyectos políticos tan profundamente diferentes. Y ello explica que Bélgica haya establecido sucesivos records de duración en ese proceso.

Así, en 1988 el Gobierno Maertens VIII requirió de 148 días de negociaciones. Sin embargo, tras las elecciones de junio de 2007, el acuerdo para formar Gobierno exigió casi el doble (282 días, hasta marzo de 2008), e hizo necesario recurrir a casi todas las figuras anteriormente mencionadas. De este modo, el Rey Alberto II nombró primero, como informador, al líder de los liberales francófonos,

56 http://elections2014.belgium.be/fr/cha/results/results_graph_CKR00000.html.

57 Concretamente, a los representativos de las corrientes políticas tradicionales (por este orden, el democristiano C-D\&V, el liberal Open VLD y el socialista sp.a) han de añadirse los ecologistas (Groen) y tres formaciones nacionalistas: la mayoritaria N-VA, el Vlaams Belang («Interés flamenco», resultado de la reconversión del «Bloque Flamenco», prohibido por la justicia belga en 2004, y considerado como un grupo «de extrema derecha xenófoba»: ASTIÉ, P., BREILLAT, D., LAGEOT, C., «Repères étrangers», Pouvoirs, n 123 , 2007 , p. 160) y la «lista Dedecker».

58 Los liberales del Mouvement réformateur, el Parti Socialiste, el Centre Démocrate Humaniste y los ecologistas de Écolo, A ellos se sumó el Front National (en 2007); y, luego, el mencionado Parti Populaire (desde 2010). En 2014, también alcanzó representación el FDF (separado del MR en 2011, desde 2015 se denomina DéFi).

59 «El rompecabezas belga ha conseguido que Bélgica sea el único Estado federal en el mundo que no tiene una democracia. Tiene dos. Los francófonos votan partidos francófonos. Los neerlandófonos, por partidos neerlandófonos. Lo que supone la división de todas las familias políticas del país. La consecuencia es que el sur hace campaña electoral contra el norte, y en el norte se hace campaña electoral contra el sur. Al fin y al cabo, no se ganan votos en la otra comunidad (...) Ha bastado una generación para que se consoliden dos opiniones públicas distintas, cuando no opuestas. El norte, Flandes, siempre vota nacionalista y a la derecha. El sur, Valonia, siempre vota socialista y por un país federal y unido». Y este clima «no se crea de la noche a la mañana. Esta semilla ha crecido alimentada, sobre todo, por los partidos políticos, deseosos de ganar votos» (DE REGOYOS, J., «Bélgica: El laboratorio nacionalista de Europa», en Cuadernos de pensamiento Político FAES, no 31, julio 2011, pp. 104-105 y 125). En conjunto, y respondiendo básicamente a la distribución de la población belga, el conjunto de los partidos flamencos recibe en torno al $60 \%$ de los votos válidos emitidos, mientras los partidos francófonos no llegan al $40 \%$. 
Didier Reynders ${ }^{60}$; posteriormente, como mediador, a Jean-Luc Dehaene, democristiano flamenco y antiguo Primer Ministro (1992-1999), con una «misión de mediación y negociación»; y finalmente, como formador de Gobierno, a Yves Leterme, líder de los democristianos flamencos y Ministro-Presidente de Flandes.

No obstante, los choques entre flamencos y francófonos provocaron que en agosto el Rey decidiera «suspender» el encargo confiado a Leterme como formador. Dos días más tarde, le encargó nuevamente iniciar «nuevos contactos» pero volvió a fracasar, por lo cual, el 30 del mismo mes el Rey encargó al Presidente de la Cámara de Representantes, el también democristiano flamenco Herman Van Rompuy, que asumiese una mission d'exploration, inaugurando así una nueva categoría que añadir a las ya conocidas. A continuación, el 29 de septiembre el Rey encargó por tercera vez a Leterme la formación de Gobierno... pero éste renunció de nuevo en diciembre. Se acordó entonces formar un «Gobierno interino», encabezado por el Primer Ministro en funciones, G. Verhofstadt, por un período de tres meses, durante los que siguieron nuevas rondas de negociaciones. Finalmente, el 20 de marzo de 2008 se anunció la firma de un acuerdo de Gobierno pentapartito ${ }^{61}$, en cuya virtud el Rey, a propuesta del Primer Ministro en funciones, nombró Primer Ministro a Yves Leterme.

En todo caso, el acuerdo de gobierno tenía fecha de caducidad, ya que los partidos flamencos establecieron ese mismo verano como fecha límite para llegar a acuerdos sobre la reforma del Estado, o la reforma institucional ${ }^{62}$. Y la imposibilidad de alcanzarlos llevó al Primer Ministro a presentar su renuncia al Rey quien, por su parte, y tras celebrar diversas consultas, decidió no admitirla, pidiéndole «que promueva al máximo las oportunidades de diálogo» institucional, para lo cual encargó a tres personalidades la misión de «examinar de qué manera pueden ofrecerse garantías para entablar de manera creíble» este diálogo ${ }^{63}$.

De cualquier modo, la inestabilidad intrínseca al sistema no había desaparecido: pocos meses más tarde (en diciembre de 2008) se formó un nuevo Gobierno

60 Ministro de Finanzas en el saliente Gobierno encabezado por el también liberal, pero flamenco, Guy Verhofstadt. Un relato más detallado de este proceso y de sus circunstancias puede verse en nuestra crónica, ya citada, «Actualidad política y constitucional...», TRC, 22, 2008.

61 Formado por democristianos flamencos (sin su socio nacionalista, que se negó a unirse a esta coalición) y valones, liberales de ambas Comunidades, y — la relativa sorpresa - los socialistas francófonos, cuya presencia rompía con la paridad de fuerzas tradicional en Bélgica.

62 Vide El País, 14 y 15 de julio de 2008, que la considera «el auténtico conflicto en el que se encuentra enzarzado el país».

63 Comunicado de Palacio del 17 de julio de 2008 (las citas proceden de Le Monde.fr y Libération.fr del 17 y 18 de julio). En cuanto a esas tres personalidades, eran dos francófonos (un diputado liberal de Bruselas, y un eurodiputado centrista) y el Ministro-Presidente, socialista, de la pequeña comunidad germanófona. Su misión era la de preparar el terreno para la «reforma del Estado», y su llamativa extracción —concretamente, la ausencia de miembros flamencos - se explicaba, al parecer, porque el partido democristiano flamenco de Leterme (mayoritario en Bélgica y, por tanto, referencia inexcusable para formar mayorías) habría exigido a los francófonos que planteasen iniciativas para convencer a la mayoría flamenca de su voluntad de diálogo y reforma. 
encabezado por otro democristiano flamenco, Herman Van Rompuy, que duró hasta noviembre de 2009, cuando su Primer Ministro fue designado Presidente del Consejo Europeo. En definitiva, y un año antes del final de la Legislatura, las nuevas elecciones de junio de 2010 alumbraron la situación parlamentaria ya descrita, que abrió un nuevo proceso de negociaciones que se alargaría más de un año: concretamente, 541 días hasta que, en diciembre de 2011, se consigue un acuerdo de Gobierno.

Naturalmente, durante todo este tiempo volvieron a sucederse todo tipo de iniciativas $^{64}$ :

- tras las pertinentes consultas, el 17 de junio el Rey nombró como informador al nacionalista flamenco Bart de Weber, líder del partido mayoritario (N-VA), cuyo informe concluía que no había bases para formar un Gobierno. Por tanto, el Rey le retiró el encargo; y

- el 8 de julio designó como préformateur al líder socialista francófono Elio Di Rupo, que había obtenido la victoria en Valonia. Éste renuncia el 29 de agosto, pero el Rey no admite la renuncia en primera instancia.

- Poco después, el 4 de septiembre, le retira esta misión, encargando a los Presidentes de ambas Cámaras como médiateurs ( «mission de médiation»).

- Ante las dificultades en las negociaciones, el 8 de octubre el Rey designa nuevamente a De Weber, esta vez como clarificateur ( «mission de clarification») de ciertos aspectos. Su informe es considerado inaceptable por los partidos francófonos, por lo cual

- El 21 de octubre el Rey designa como conciliateur royal («mission de conciliation») al socialista flamenco Johan Vande Lanotte quien, tras varios intentos infructuosos, y otras renuncias previas, finalmente presenta su dimisión el 26 de enero de 2011.

- El 2 de febrero el Rey nombra como informateur al liberal francófono Didier Reynders ${ }^{65}$. Éste presenta su informe un mes más tarde.

- A continuación, es el Presidente de los democristianos flamencos, Wouter Beke, quien es nombrado médiateur ( «mission de médiation»).

- El 16 de mayo, Elio Di Rupo le sucede, como formateur, con el encargo de formar Gobierno. El 4 de julio presenta un documento que habría de

64 Sobre este período, pueden encontrarse aún interesantes crónicas recapitulatorias en medios belgas La libre Belgique (http://www.lalibre.be/actu/politique-belge/541-jours-en-19-dates-cles-51b8dd94e4b0de6db9c3db3f; https://www.rtbf.be/lapremiere/article/detail_revue-de-presse-tous-vos-journaux-sont-focalises-sur-di-rupo-1er?id=7195773\&redirect ) o franceses (http://www.parismatch.com/Actu/International/ Belgique-541-jours-de-crise-et-enfin-un-gouvernement-150587); y un amplio volumen de información y enlaces en la utilísima —aunque no siempre fiable_ Wikipedia (https://fr.wikipedia.org/wiki/Crise_ politique_belge_de_2010-2011\#cite_note-31).

65 Y ese mismo día, dada la duración de la crisis, solicita al Primer Ministro en funciones (todavía Y. Leterme) que presente al Parlamento un Presupuesto para 2011 y adopte las disposiciones necesarias para responder a las exigencias europeas en materia de política presupuestaria y reformas estructurales. 
servir de base para las negociaciones, y que es inmediatamente rechazado por los nacionalistas flamencos. Tras varios meses de negociaciones, pese a la presión de la Unión Europea y de los mercados financieros, renuncia el 21 de noviembre; pero

- Ante la degradación de sus ratings financieros y el aumento de la prima de riesgo belga, los seis partidos de las tres «familias políticas» tradicionales llegan a un principio de acuerdo, por lo que el Rey encarga nuevamente a Di Rupo formar un Gobierno tan rápidamente como sea posible (26 de noviembre).

- Finalmente, el acuerdo entre los partidos se publica el 2 de diciembre, y el nuevo Gobierno presidido por Di Rupo, altamente continuista respecto al anterior, obtiene la confianza de la Cámara de Representantes el 10 del mismo mes: Bélgica no tenía un Primer Ministro francófono desde 1979 (E. Leburton); ni uno originario de Valonia desde 1974 (P. Vanden Boeynants).

Afortunadamente, el proceso no se repetiría tras las siguientes elecciones, celebradas el 25 de mayo de 2014. En esta ocasión fueron necesarios «solo» cuatro meses y medio de negociaciones para acordar la formación de un Gobierno con una configuración inédita hasta la fecha: presidido por el liberal (otra vez) francófono Charles Michel, y formado por miembros de otros tres partidos, todos ellos flamencos y amplísimamente mayoritarios ${ }^{66}$. En esta ocasión, el Rey nombró como informateur a Michel, quien - tras varias prórrogas en su misión- presentó su informe final el 22 de julio. Ese mismo día, el Rey le designó — junto con el Presidente saliente de Flandes y hoy vicepresidente belga, el líder democristiano flamenco Kris Peeters- como formateurs, encomendándoles la «mission de formation» de un nuevo Gobierno federal, que finalmente pudo nombrarse en octubre $^{67}$.

Por consiguiente, y en virtud de la mencionada regla constitucional de la paridad entre Ministros francófonos y flamencos, la mitad de los Ministros incluyendo a su Presidente- son miembros del MR (partido minoritario de la coalición), y los otros siete (además de los cuatro Secretarios de Estado, a los que no afecta esta regla) de los tres partidos flamencos. Una composición, pues, no sólo inédita, sino incluso improbable y tendencialmente inestable ${ }^{68} \ldots$ para un

66 El Mouvement Réformateur del Primer Ministro consiguió un 9'64\% de votos y 20 escaños; resultados pues inferiores a los de cada uno de los tres partidos flamencos de la coalición (N-VA, CD\&V y Open VLD), que sumaron el $41 \%$ (20’4, 10’85 y 9'8, respectivamente) y 65 escaños (33, 18 y 14).

67 https://www.rtbf.be/info/belgique/detail_charles-michel-decharge-de-sa-mission-kris-peetersest-au-palais?id=8320221.

$68 \mathrm{Y}$ así, las tendencias nacionalistas de algunos ministros se hicieron patentes ya en el acto solemne de su juramento: véase http://www.elmundo.es/internacional/2014/10/11/54396c6be2704e5e6d8b457e. html. De ahí que no resulte extraño que popularmente se conociese esta coalición con el expresivo sobrenombre de «coalición kamikaze». 
Gobierno explícitamente centrado en aspectos socio-económicos, y que trata de evitar más debates territoriales e institucionales. Circunstancias que, dicho sea de paso, seguramente contribuyen a explicar algunos acontecimientos recientes, poco explicables desde España.

\section{CONCLUSIÓN: UN MODELO MUY DISCUTIBLE, Y NO IMPORTABLE}

A la vista de cuanto hasta aquí se ha expuesto, y en particular de la mera enunciación de todas las vicisitudes que rodean la formación del Gobierno en Bélgica, resulta difícilmente sostenible que este modelo (como el holandés, del que tampoco se diferencia mucho en algunos aspectos pese a la reforma de éste) sea más eficaz que el español, u otros concebibles.

Desde una perspectiva más general, los datos apuntan también que los elementos comunes entre las Monarquía parlamentarias belga y española encuentran claros límites derivados de las diferentes circunstancias y prácticas políticas, que - como es lógico - constituyen los principales condicionantes para formar mayorías en los sistemas representativos. Y, en cuanto a la concreta cuestión que aquí más nos interesa, revela que las (por otra parte, escasas) voces que en España parecen reclamar (muy tímidamente, como se ha visto) una mayor implicación de la Corona en el proceso de formación de mayorías parlamentarias y gubernamentales no son seguramente conscientes de que modelos que así lo prevén, como el belga, son difícilmente importables.

Y ello no sólo por la antedicha razón de eficacia. Sino, sobre todo, porque esa mayor implicación (o «margen de impulso») puede llegar a poner en riesgo la posición super partes del Monarca, en tanto aparezca vinculado a los mismos y, por tanto, a su eventual éxito o fracaso. De ahí que el debate sobre este punto en Bélgica siga más bien la tendencia contraria, que es por otra parte la más ajustada a la evolución de la Jefatura del Estado —especialmente, de la Monarquía - en los sistemas parlamentarios, hasta concluir que «si, en un futuro próximo, una reforma constitucional estableciese [en Bélgica] una Monarquía verdaderamente simbólica, ello no supondría una revolución, sino la confirmación de una prolongada evolución ${ }^{69}$.

TITLE: The Crown's role in the appointment of the Belgian Prime Minister: a not importable model

AвSTRACT: Alter the failure to build a parliamentary majority and the need to bold new elections in Spain in 2016, certain social and political sectors have pointed out the convenience of reviewing the Spanish

69 POPELIER, P., LEMMENS, K., ob. cit., p. 179. 
procedures for appointing a new Government. In particular, the role of the King has been analysed, trying to suggest new formulae capable of granting stability and surmounting the political fragmentation which resulted from the last general elections. The paper focuses mainly on the Belgian model for appointing a government, which reserves an important role for the King. It tries to show that, taking into account not only the - formal and informal - rules, but also the political practice, the Belgian model does not appear at all as more efficient than the Spanish one. And, what is more important from a systemic point of view, it allows a deeper debate on the political and institutional position of the Head of the State.

RESUMEN: Tras la incapacidad de construir una mayoría parlamentaria y la necesidad de convocar nuevas elecciones en España en 2016, ciertos sectores sociales y políticos señalaron la conveniencia de revisar los procesos de investidura. En particular, se hizo hincapié en el papel del Rey, tratando de sugerir nuevas fórmulas capaces de otorgar estabilidad y superar la fragmentación política resultante de las últimas elecciones generales. El presente estudio se centra principalmente en el modelo belga, que reserva un papel importante para el Rey, alcanzándose la conclusión de que este modelo no presenta una mayor eficiencia política que permita pensar en tratar de trasladar a nuestro sistema algunas de sus previsiones.

KeY words: Government. Head of State. Parliamentary system.

Palabras Clave: Gobierno.Jefe de Estado. Sistema parlamentario.

FECHA DE RECEPCIÓN: 21.12.2017

FECHA DE ACEPTACIÓN: 01.02.2018 